\title{
Explorando a ferramenta de programação em design: um estudo sobre grasshopper
}

\author{
Exploring algorithmic design: a study about Grasshopper \\ - Yuri Assis Pinto \\ Universidade Federal de Santa Catarina, Brasil \\ yuriassispinto@gmail.com \\ - Regiane Pupo \\ Universidade Federal de Santa Catarina, Brasil \\ regipupo@gmail.com
}

\begin{abstract}
The current research explores the experience of introduction of algorithmic design associated with digital fabrication, for an audience of architecture and design students without any previous knwoledge in the field. Aiming the discussion and aplicabillity of the algoritghmic design it was created a workshop titled "Introduction to parametric design", for graduate and pos graduate students at the Federal University of Santa Catarina. In this workshop was explored the aplicabilities of the parametric design in the field of academic research, ending with the use of digital fabrication methods.
\end{abstract}

Keywords: Parametric Design, Grasshopper, Generative Systems, Digital Technology

\section{Introdução}

Projetar consiste em fundir o imaginário com a realidade do ambiente construído. Seja o projeto de um produto ou de uma arquitetura, o projetista se depara com questões físicas e matemáticas que restringem o objeto final. A gravidade, por exemplo, é um fator determinante para qualquer projetista. Por muito tempo, o modo com que os arquitetos projetavam era através do papel, lápis e borracha. Como Woodbury (2010) afirma, ferramentas como réguas, esquadros, compassos, entre outros, foram adicionadas para que esses desenhos fossem o mais precisos possível.

Já Evans (1997) nota a desvantagem em que os arquitetos trabalham quando comparado a outras profissões, como pintores e escultores, no que diz respeito ao empenho sob o objeto. $\mathrm{O}$ arquiteto quase sempre está trabalhando sobre $\mathrm{O}$ desenho e não diretamente com o objeto final de seu estudo. Nas últimas décadas, porém, a tecnologia trouxe novas ferramentas projetuais. Softwares de desenho 2D e 3D (CAD - Computer Aided Design) e de fabricação (CAM - Computer Aided Manufacturing), possibilitam um maior entendimento sobre este objeto final, bem como facilitam correções nos desenhos e na modelagem digital quando comparadas ao desenho manual. Aos poucos, explora-se esta nova interface de trabalho: a tecnologia digital.

Outros autores como Celani (2013) e Davis (2013) demonstram que os processos digitais podem ser relevantes para o cenário da construção civil, inclusive no Brasil, uma vez que o design e a fabricação digital aproximam o projetista do seu objeto de pesquisa. Nesse sentido, tenta-se mostrar como o processo digital contribui para criar soluções inovadoras, interativas e complexas, na medida em que as preocupações com representações do tipo 2D e 3D de objetos complexos não mais limitam o pensamento daquele que projeta, na produção e manufatura, caso ele utilize as ferramentas digitais.

Para isso, é necessário um conhecimento de ferramentas de modelagem, edição, materialização e montagem. Ainda, novas tecnologias de projeto digital, como softwares de parametrização com programação paramétrica visual, estão diferenciando o cenário de processo projetual. Este artigo, além de relatar uma experiência de projetação, manipulação e materialização da forma com novas tecnologias, introduz uma nova sistemática de processo de projeto, em um grupo leigo frente ao desenho paramétrico e suas ferramentas.

\section{Metodologia}

Um dos métodos para se pensar o processo digital, segundo Celani, Vaz e Pupo (2013), é o sistema generativo. Nesse, o projetista não se preocupa em solucionar um problema em particular em um contexto específico, mas sim em definir um método que possibilite a resolução de problemas semelhantes, em diferentes contextos e com características ligeiramente distintas. O design paramétrico é um exemplo desse 
sistema. Ele permite ao projetista criar/programar conexões geométricas, matemáticas, físicas e materiais por meio do uso de um software que permitirá a visualização em tempo real desses parâmetros em ação (live render). Este método é muito diferente do que é ensinado em grande parte dos cursos de Arquitetura, onde o projetista somente modela a forma final de seu produto.

Para tanto, busca-se mostrar que a seleção e determinação de parâmetros pertinentes pode gerar um esquema, no qual o software seguirá para atingir formas ideais pretendidas. O projetista é responsavel pelos códigos que determinam este(s) objeto(s) final(ais). Para Leach (2014, p.36), técnicas algorítimicas são baseadas no uso de códigos enquanto que técnicas paramétricas se baseiam na manipulação da forma. São, portanto, técnicas distintas. Isso gera uma gama de resultados adequados, facilitando testes estruturais, com usuários e de situação e implantação, por exemplo. Nesse sentido, o modelo paramétrico pode ser de grande relevância.

De acordo com Davis (2013) um modelo paramétrico é singular pelo modo como é gerado e não pelo fato de conter parâmetros ou a capacidade de alteração. Isto é, por meio da programação é que um projeto se torna paramétrico. Segundo Leach (2014, p.34), no contexto do design contemporâneo, parametricismo refere-se à utilização de softwares de modelagem paramétrica que, em contraste com programas de modelagem baseados em dados geométricos, relacionam dimensões e parâmetros a geometria, permitindo ajustes que afetam todo o design. Leach $(2014$, p.36) considera o termo design paramétrico como uma nova técnica digital que aplica um novo processo de projeto ou metodologia de design, porém está sendo adotado como uma nova expressão estética ou estilo arquitetônico.

Com este novo vocabulário e a nova sistemática do processo projetual que se tem mostrado em experiências de diversas origens, escolheu-se o Grasshopper como ferramenta de concepção projetual para a presente pesquisa. $O$ Grasshopper éum editor gráfico de algoritmos generativos, que funciona como plugin associado ao programa de modelagem Rhinoceros. Sua interface, facilitada para designers, possibilita a criação e programação de algoritmos sem a necessidade de domínio de linguagem de programação e script. Embora sua interface seja intuitiva, suas funcionalidades matemáticas são complexas, o que possibilita o total entendimento do projetista sob o objeto, uma vez que ele é responsável pela criação e conexão dos parâmetros que geram a forma. Esse processo, depois de assimilado, facilita diversas etapas de projeto por permitir uma interação geométrica direta e facilmente editável pelo projetista.

Esta abordagem, por possibilitar a criação de sistemas interligados, é introduzida graficamente objetivando uma compreensão de diferentes interfaces, inputs e configurações necessárias ao que se pretende projetar. A figura 1 é um exemplo em que os parâmetros iniciais são apenas duas curvas. Por meio da programação em Grasshopper, essas curvas foram subdivididas, copiadas, movimentadas, interligadas e modificadas. O resultado é uma estrutura treliçada, em que o número de subdivisões, altura da estrutura, largura do material, etc., são facilmente editáveis de forma a atingir o melhor resultado para o projeto proposto.

A leitura da programação se dá da esquerda para a direita, considerando o parâmetros iniciais (input) como sendo as duas curvas e o resultado (output) dessa modelagem sendo a geometria do produto, neste caso, um galpão. As aplicações para esse tipo de abordagem em projeto são muito amplas. O projetista, seja ele arquiteto, designer ou engenheiro, estipulará as relacões desejadas de forma a resultar uma gama de possíveis respostas para o projeto. Nesse exemplo, o raio dos arcos conectores, o número de divisões nas curvas, a altura final do objeto e a espessura do material resultarão em diferentes formas, facilitando a vizualização e edição de geometrias complexas.

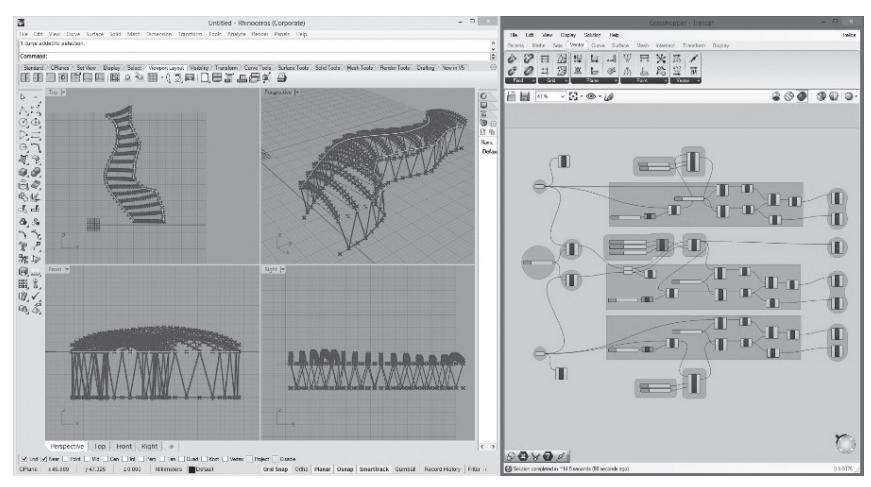

Figura 1.

Como complemento à nova sistemática de projeto e consolidando a materialização como forma de validação às alternativas alcançadas com a modelagem, a fabricação digital se mostra importante quando presente em todas as fases do processo. As tecnologias de impressão 3D, corte e desbastes automatizados, com equipamentos de controle numérico ou de corte laser, possibilitam um imediato entendimento das soluções previamente geradas pelos sistemas generativos.

Neste sentido, visando a compreensão desta nova abordagem em design, foi criado o workshop, intitulado "Introdução ao Design Paramétrico", em que a ferramenta Grasshopper é introduzida e explorada nas etapas de concepção, desenvolvimento, modelagem e a fabricação digital, participando durante todo o processo projetual.

\section{O Workshop}

Ao longo de 3 meses foi realizado um workshop com alunos de graduação e pós-graduação em Arquitetura e Design da Universidade Federal de Santa Catarina, afim de se introduzir esta nova ferramenta e sistemática projetuais. Com um público totalmente leigo em aspectos referentes aos software e hardware escolhidos, as atividades foram desenvolvidas por meio de exercícios práticos que variaram 
desde a geração, edição e subdivisão de superfície, domínios matemáticos e arranjos, até o uso da fabricação digital e suas potencialidades. Esta última etapa foi conduzida no PRONTO3D - Laboratório de Prototipagem e Novas Tecnologias Orientadas ao 3D, na UFSC, em Florianópolis, que conta com os principais equipamentos para materialização automatizada, cortadora laser, impressão 3D e Fresadora CNC.

Inicialmente, após o contato e familiarização da interface do software e sua nova sistemática de input, um exercício prático introdutório pôde explorar as potencialidades primárias de uma modelagem simples de uma superfície plana que se molda por meio de cinco curvas nela sobrepostas (Figura 2). Esta fase foi importante para o entendimento entre a parte gráfica de programação e o desenho propriamente dito, evidenciando, para o iniciante neste tipo de programação, que conhecimentos de geometria descritiva, espacialidade tridimensional e proporção são igualmente essenciais.
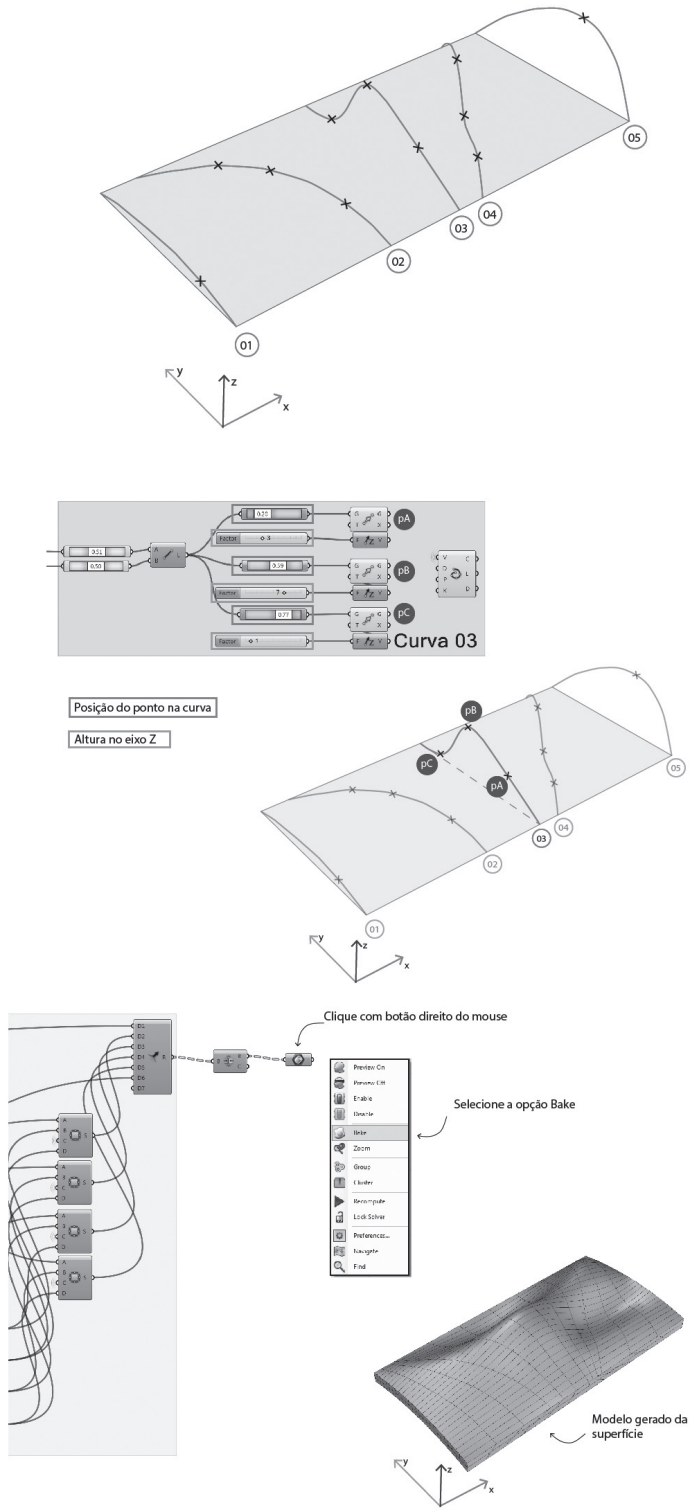

Figura 2: Exercício inicial. Fonte: Autores.
A segunda etapa, já focada na materialização do objeto projetado, se voltou para o fatiamento, encaixe e planificação do produto obtido e sua preparação para o corte laser (Figura 3). Neste estágio, se considerou todas as variáveis envolvidas para o corte, como tamanho máximo da peça, espessura do material, potências e velocidades de corte. Cada aluno pôde, atento às potencialidades e limitações do equipamento de corte, sempre sob a supervisão de um técnico habilitado, cortar, montar e concluir o modelo que acabara de projetar (Figura 4).

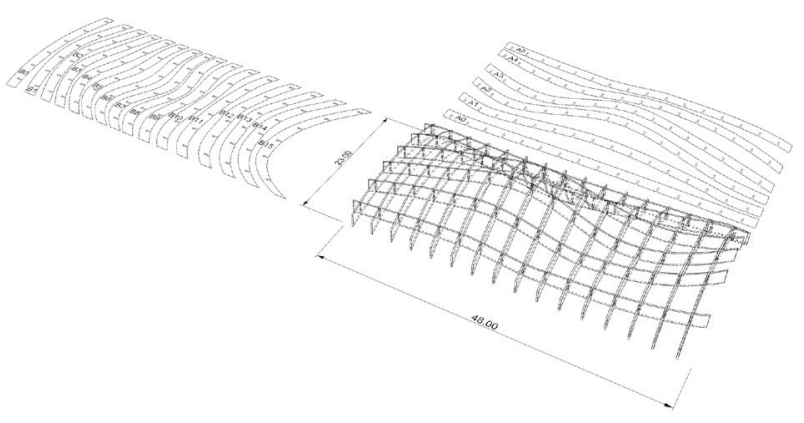

Figura 3: Planificação. Fonte: Autres.

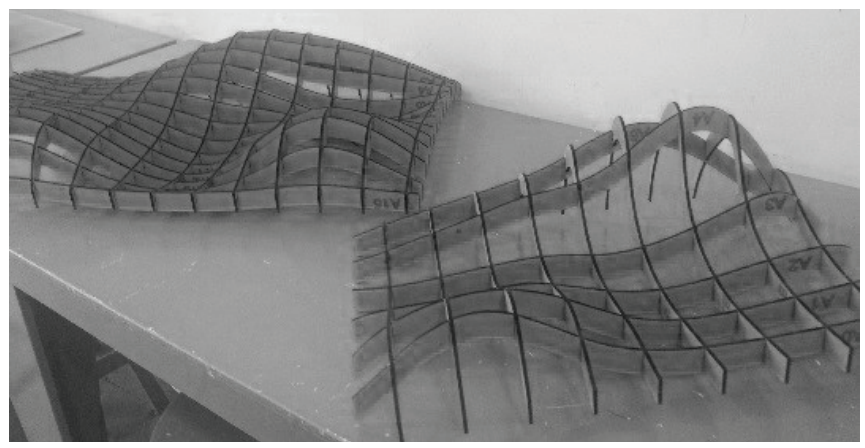

Figura 4: Materialização. Fonte: Autores.

A proposta para o exercício final foi o projeto e construção de uma parede divisória modular que pudesse servir para fechamento (visual e não acústico)além de ser versátil ao ponto de se transformar para a criação de mobiliário, tais como superfícies de assento e apoio.Para isso, foi realizada uma programação dos módulos de forma a otimizar as peças, definir seus encaixes, dimensões e espessura do material (Figura 5).

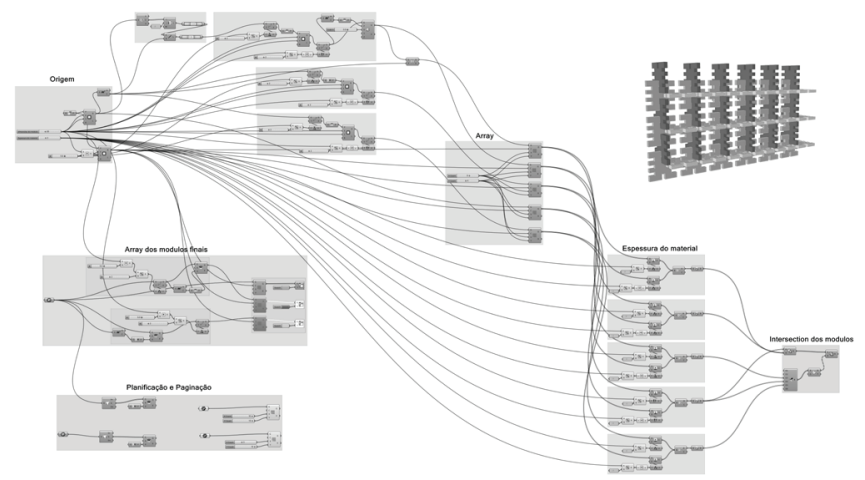

Figura 5. 
Durante a etapa generativa do projeto, algumas configurações foram exploradas no software com o objetivo de investigar suas potencialidades, direcionando, ao longo do processo, para a fabricação dos módulos (Figura 6). Assim que decidida alguma configuração, havia a imediata preparação para o corte laser, nos moldes do exercício introdutório, a fim de se testar os encaixes e as possíveis modulações das peças. Nesta etapa pôde-se observara interação dos alunos com as formas materializadas, auxiliando na definição dos possíveis arranjos e encaixes. Enquanto por um lado a tecnologia de programação permitiu uma exploração nos módulos, a interatividade com o modelo físico foi determinante para catalogação dos possíveis arranjos (Figura 7).

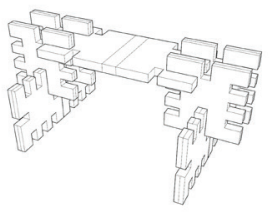
Banco formado a partir de 4 módulos
pequenose 1 módulo retangular

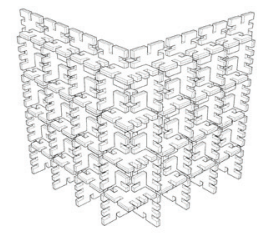

Junçăo em $90^{\circ}$

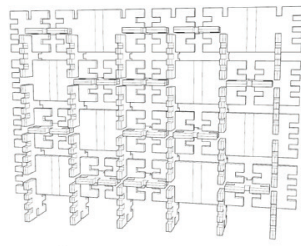

A parede com arranjo em zig-zag entre móulos quadrados e retangulares

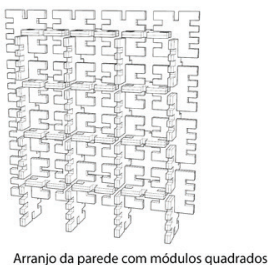

Figura 6: Possiveis configuraçoes. Fonte: Autores.

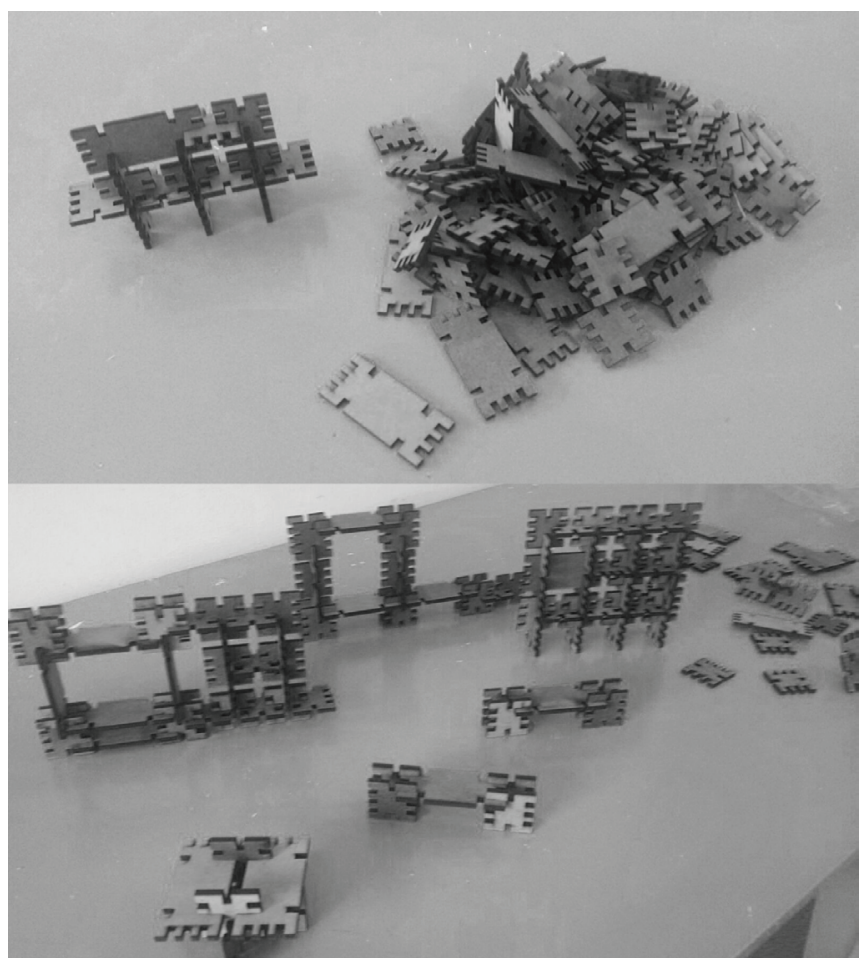

Figura 7: Testes em corte laser. Fonte: Autores.
A terceira etapa consistiu em utilizar uma fresa CNC (Computer Numerc Control) a qual seria utilizada na fabricação dos protótipos em escala real. Desta forma, a avaliação dos produtos quanto a questões como construtibilidade, proporção, encaixes, materiais utilizados, segurança, ergonomia e estética tem o respaldo do produto pronto, acabado e testado. Novamente, seguindo a sistemática das etapas anteriores, foram estabelecidos alguns protocolos, agora direcionados a um equipamento que utiliza parâmetros diferenciados. Até o fechamento deste artigo, a fabricação de um módulo havia sido completa e sua análise iniciada. Nesta fase, os projetistas têm a capacidade de, após análise dos fatores já citados, decidir pela continuidade ou modificação do produto, com sua posterior fabricação. (Figura 8).

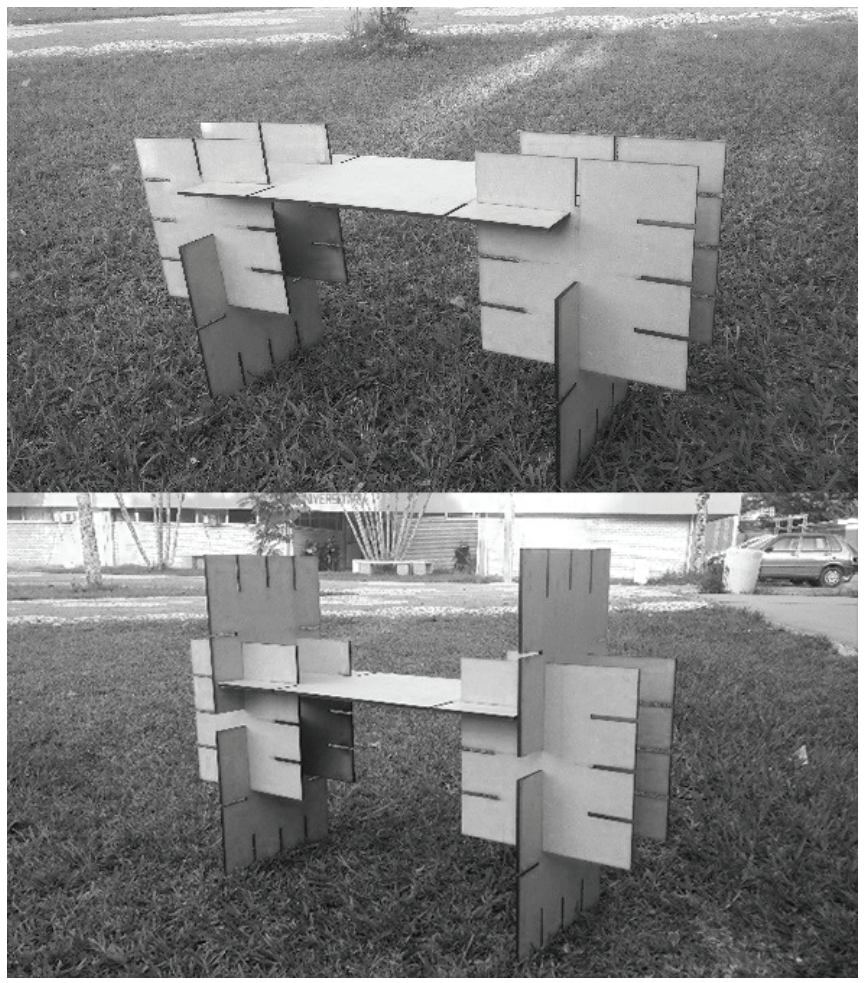

Figura 8: Testes em CNC escala 1:1. Fonte: Autores.

Esta abordagem projetual que inclui o ciclo parametrização $\mathrm{x}$ fabricação $\mathrm{x}$ análise $\mathrm{x}$ fabricação facilita a compreensão, vizualização, edição e fabricação de arquiteturas, produtos e sistemas. A pesquisa de projeto valendo-se da tecnologia é imprescindível, uma vez que facilita o entendimento do projetista sobre o desenvolvimento de seu produto até sua finalização. Entender como as relações geométricas, topográficas, ergonômicas, subjetivas, etc. alteram o produto final, resultará em uma nova arquitetura. Uma arquitetura naqual o projetista 
detém total controle sobre o que propõe, já que ele participa desde a concepção até manufatura de seu objeto.

\section{Resultados e Discussão}

No âmbito desse Workshop, procurou-se obter um entendimento maior do possível papel do design paramétrico no ambiente construído brasileiro, o ensino dessa ferramenta, as dificuldades dos alunos ao modelar de forma paramétrica e as melhores formas de se aplicar esta ferramenta. Éimportante relatar que os participantes não tinham nenhuma experiência prévia de qualquer uma das tecnologias envolvidas, software ou hardware de materialização, e sua interação e compreensão se mostrou plena e completa a partir do momento que um contato mais direcionado é estabelecido. Com isso, podese concluir que ferramentas digitais e softwares paramétricos, quando bem aplicados, podem auxiliar em muito o processo projetual. A atuação da ferramenta pode começar desde a concepção e ir até a fabricação, o que possibilita total entendimento do projetista em seu trabalho.

\section{Referências}

Celani, Vaz e Pupo (2013). Sistemas Generativos de Projeto: Classificação e Reflexão sob o ponto de vista da representação e dos meios de produção. Revista Brasileira de Expressão Gráfica. Vol.1, No.1.

Woodbury, Robert (2010). Elements of Parametric Design. Evans, Robin (1997). Translations from Drawing to Building and Other Essays.

Davis, Daniel (2013). Tese de Doutorado. Modelled on Software Engineering: Flexible Parametric Models in the Practice of Architecture. RMIT University.

Leach, Neil (2014). Parametrics Explained. Next Generation Building. Vol. 1, No. 1. 